\title{
Cooling Rate Dependence of Boron Distribution in Low Carbon Steel
}

\author{
DONG JUN MUN, EUN JOO SHIN, KYUNG CHUL CHO, JAE SANG LEE, \\ and YANG MO KOO
}

\begin{abstract}
The behavior of boron (B) segregation to austenite grain boundaries in low carbon steel was studied using particle tracking autoradiography (PTA) and secondary ion mass spectroscopy (SIMS). An effective time method was used to compare the cooling rate (CR) dependence of this segregation during continuous cooling and its time dependence during isothermal holding. Comparison of these segregation behaviors has confirmed that the CR dependence of B segregation agrees well with its time dependence and is mainly a result of the phenomenon of nonequilibrium segregation. Based on the $\mathrm{CR}$ dependence of $\mathrm{B}$ segregation, the continuous cooling transformation behavior of B-bearing steel as compared with B-free steel was also investigated using dilatometry and microstructural observations. The addition of a small amount of B to low carbon steel retarded significantly the austenite-to-ferrite transformation and finally expanded the range of cooling programs that result in the formation of bainitic microstructures. Analysis of the B distribution has confirmed that this retardation effect of $\mathrm{B}$ on ferrite transformation is attributed to the CR dependence of B segregation to austenite grain boundaries during cooling after austenitization.
\end{abstract}

DOI: 10.1007/s11661-011-0997-0

(C) The Author(s) 2011. This article is published with open access at Springerlink.com

\section{INTRODUCTION}

THE addition of a small amount of boron (B) remarkably increases the hardenability of low carbon, low alloy steels. ${ }^{[1-5]}$ This beneficial effect on hardenability occurs because segregation of $\mathrm{B}$ atoms to austenite grain boundaries reduces the grain boundary energy and thus retards transformation of austenite to ferrite. B atoms are easily segregated to the austenite grain boundaries during general heat treatment and have a strong tendency to interact with lattice imperfections. ${ }^{[6]}$ In general, the grain boundary segregation of $\mathrm{B}$ in steel occurs by two mechanisms: equilibrium and nonequilibrium segregation. ${ }^{[7]}$ Equilibrium grain boundary segregation (EGS) occurs by the movement of solute atoms from inside the grain matrix to loosely packed regions such as grain boundaries, thus reducing the grain boundary free energy. Nonequilibrium grain boundary segregation (NGS) occurs during cooling from high temperatures by the diffusion of vacancy-solute complexes toward grain boundaries. The NGS of B is generally accepted to be the usual dominating process in steel. ${ }^{[8-10]}$

DONG JUN MUN, Postdoctoral Candidate, JAE SANG LEE, Associate Professor, and YANG MO KOO, Professor, are with the Graduate Institute of Ferrous Technology, Pohang University of Science and Technology, Pohang 790-784, Republic of Korea. Contact e-mail: koo@postech.ac.kr EUN JOO SHIN, Senior Researcher, is with the Neutron Science Division, Korea Atomic Energy Research Institute, Daejeon 305-353, Republic of Korea. KYUNG CHUL $\mathrm{CHO}$, Senior Researcher, is with the Steel Making Research Group, Technical Research Laboratories, POSCO, Gwangyang 545-090, Republic of Korea.

Manuscript submitted July 20, 2011

Article published online November 17, 2011
According to the mechanism of the NGS, solute B atoms are transported to the grain boundaries after forming complexes with vacancies. A large number of supersaturated vacancies can be produced in a material during quenching, irradiation, or deformation, and thus, NGS of B can be observed through these kinds of processes. In quenching-induced segregation, ${ }^{[11-13]}$ supersaturated vacancies formed during quenching from a higher temperature to a lower temperature are annihilated at grain boundaries during isothermal holding; then vacancy-boron complexes diffuse from the grain interior to the grain boundaries along the vacancy gradients with an increasing holding time (HT) at a holding temperature $T_{H}$, and the maximum grain boundary segregation of $\mathrm{B}$ occurs at a certain time that is generally known as the critical time. ${ }^{[12]}$ NGS caused by diffusion of vacancy-boron complexes gradually disappears if sufficient time is allowed for the system to reach full equilibrium. This is a very important concept in understanding NGS of B in steel.

The purpose of this study is to investigate the CR dependence of B segregation to grain boundaries in low carbon steel. Although the grain boundary segregation of $\mathrm{B}$ during the continuous cooling ${ }^{[9]}$ and isothermal holding ${ }^{[13]}$ process has been studied by some researchers, systematic comparison of this segregation during the two processes has not been made, which is very necessary to confirm the segregation mechanism of $\mathrm{B}$. Based on the effective time method, ${ }^{[14]}$ the CR dependence of grain boundary segregation of B was systematically examined through its HT dependence. A comparison between the CR dependence and the HT dependence of B segregation to grain boundaries will 
lead to a better understanding of the grain boundary segregation mechanism of B in steel.

\section{EXPERIMENTAL PROCEDURE}

Three types of low carbon steel were used in this study (Table I):

$\mathrm{B}$-free steel is the base steel without $\mathrm{B}$ and molybdenum (Mo); B-bearing steel contains 20 ppm B; Mo-B steel contains both B and Mo. Many researchers ${ }^{[8-10,13,15-17]}$ have used Mo-B steel to study the B segregation phenomenon because the addition of Mo in B-bearing steel suppresses carbon diffusion and thus prevents solute $\mathrm{B}$ from forming $\mathrm{Fe}_{23}(\mathrm{C}, \mathrm{B})_{6 .}{ }^{[15,16]} \mathrm{Ti}$ was added to the steels to sequester the nitrogen as TiN. To examine the effect of B addition on phase transformation, B-free steel was compared to B-bearing steel. The steel ingots were prepared using laboratory vacuum induction melting, then hot-rolled into 30-mm-thick plates, and finally cooled in ambient air to room temperature (RT). Cylindrical samples (diameter $4 \mathrm{~mm}$, length $12 \mathrm{~mm}$ ) were machined from the plates with the longitudinal axis parallel to the rolling direction.

Heat treatment was performed using a hot deformation simulator with a dilatometer in an inert atmosphere of argon gas. Two heat treatment patterns were employed to examine the distribution behavior of $\mathrm{B}$ (Figure 1). Treatment (a) was continuous cooling; Mo-B steel was heated from RT to $1473 \mathrm{~K}\left(1200^{\circ} \mathrm{C}\right)$ at $10 \mathrm{~K} /$ second, austenitized for 300 seconds, and then cooled to $\mathrm{RT}$ at a cooling rate $\mathrm{CR}$ from 1 to $100 \mathrm{~K} /$ second. Treatment (b) was isothermal holding; Mo-B steel was heated from RT to $1473 \mathrm{~K}\left(1200^{\circ} \mathrm{C}\right)$ at $\mathrm{CR}=10 \mathrm{~K} /$ second, austenitized for 300 seconds, then quenched to $1173 \mathrm{~K}\left(900{ }^{\circ} \mathrm{C}\right)$ at $\mathrm{CR}=50 \mathrm{~K} /$ second. After holding for times between 0 and 1000 seconds at $1173 \mathrm{~K}\left(900^{\circ} \mathrm{C}\right)$, the specimen was quenched to RT by water spraying. The microstructures of the specimens were examined using an optical microscope after being etched with 4 pct picral etchant.

To examine the continuous cooling transformation behavior, both B-free and B-bearing steels were austenitized for 300 seconds at $1173 \mathrm{~K}\left(900^{\circ} \mathrm{C}\right)$, and then continuously cooled to RT at $1 \leq \mathrm{CR} \leq 60 \mathrm{~K} /$ second. It is generally known that the effect of $\mathrm{B}$ on the hardenability of the steel decreases with increasing austenitizing temperature ${ }^{[3,15,18,19]}$, and thus, the low austenitizing temperature of $1173 \mathrm{~K}\left(900^{\circ} \mathrm{C}\right)$ was chosen to examine the effect of $\mathrm{B}$ on the austenite-to-ferrite transformation in low carbon steel.

The distribution of $\mathrm{B}$ in the specimens was determined using particle tracking autoradiography (PTA) and secondary ion mass spectroscopy (SIMS). PTA is based on detection of the alpha-particles emitted from the thermal neutron ${ }^{10} \mathrm{~B}(\mathrm{n}, \alpha)^{7} \mathrm{Li}$ reaction in a solidstate track detector. PTA has a B-detection sensitivity of $1 \mathrm{ppm}$ and a spatial resolution of $2 \mu \mathrm{m} .{ }^{[20]}$ Cellulose nitrate films were used as detecting foils. Specimens were irradiated at a thermal neutron flux of $1.0 \times 10^{17} \mathrm{n} /\left(\mathrm{m}^{2} \mathrm{~s}\right)$ for 6 hours. After irradiation, films were etched in an aqueous solution of $2.2 \mathrm{~N} \mathrm{NaOH}$ at

Table I. Chemical Composition of the Steels (weight percent)

\begin{tabular}{lccccccccrrr}
\hline Steel & $\mathrm{C}$ & $\mathrm{Si}$ & $\mathrm{Mn}$ & $\mathrm{Cr}$ & $\mathrm{Ni}$ & $\mathrm{Mo}$ & $\mathrm{Ti}$ & $\mathrm{Al}$ & $\mathrm{B}$ & $\mathrm{N}$ & $\mathrm{Fe}$ \\
\hline B-free & 0.072 & 0.516 & 2.000 & 0.304 & 0.204 & - & 0.018 & 0.029 & - & 0.0044 & Bal. \\
B-bearing & 0.067 & 0.510 & 2.000 & 0.304 & 0.204 & - & 0.020 & 0.025 & 0.0021 & 0.0041 & Bal. \\
Mo-B & 0.070 & 0.514 & 2.000 & 0.296 & 0.201 & 0.206 & 0.021 & 0.024 & 0.0022 & 0.0044 & Bal. \\
\hline
\end{tabular}

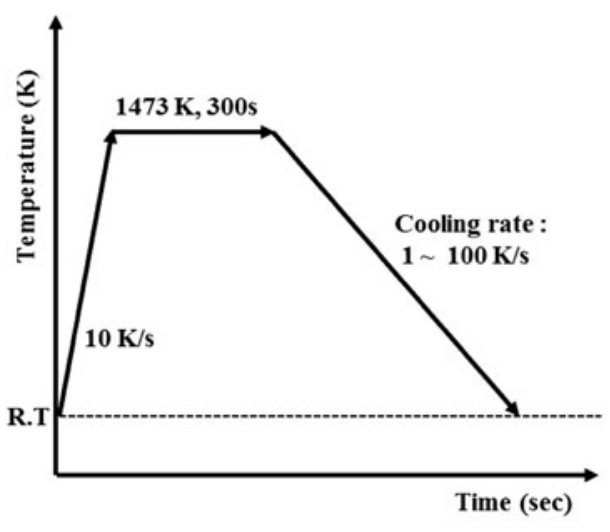

Treatment

(a)

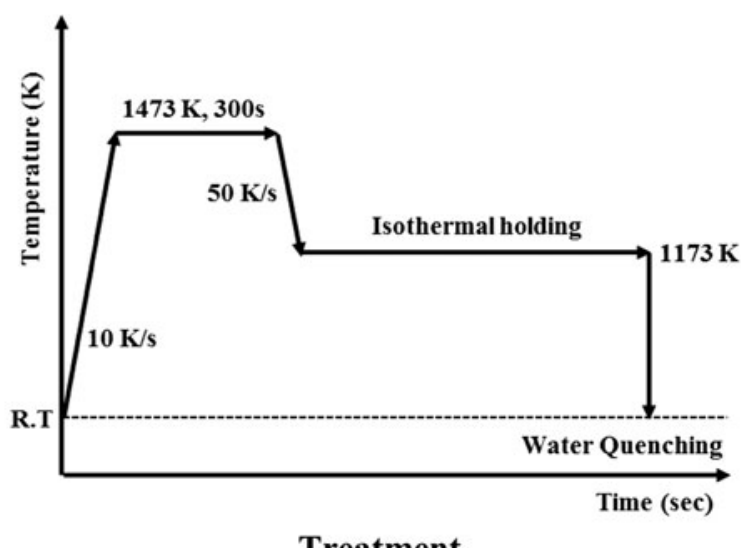

Treatment

(b)

Fig. 1-Schematic diagram of the procedure of heat treatment: $(a)$ continuous cooling treatment and $(b)$ isothermal holding treatment. 
$328 \mathrm{~K}\left(55^{\circ} \mathrm{C}\right)$ for 9 minutes. The etched films were examined using the optical microscope. SIMS is also a very powerful technique for the study of $\mathrm{B}$ distribution in steel. A Cameca IMS6F instrument (CAMECA Instrument Inc., Gennevilliers, France) using $12.5 \mathrm{keV}$ $\mathrm{O}_{2}{ }^{+}$as primary ions was employed to examine the $\mathrm{B}$ distribution. The negative secondary ions emitted from the surface were used to obtain mass-resolved ion micrographs. SIMS has a spatial resolution of approximately $1 \mu \mathrm{m}$ and a B-detection sensitivity of less than 10 ppm. ${ }^{[21]}$

\section{RESULTS}

\section{A. Cooling Rate Dependence of Boron Distribution in Low Carbon Steel}

The effect of the CR on the B distribution in the Mo-B steel is illustrated in Figure 2. After cooling from $1473 \mathrm{~K}$ $\left(1200{ }^{\circ} \mathrm{C}\right)$ at $\mathrm{CR}=100 \mathrm{~K} /$ second, $\mathrm{B}$ was not clearly detected at grain boundaries (Figure 2(a)), but the amount of grain boundary segregation of B increased with decreasing $C R$ to a maximum at $\sim 10 \leq \mathrm{CR} \leq 20 \mathrm{~K} /$ second and then decreased as $\mathrm{CR}$ decreased further. The $\mathrm{B}$
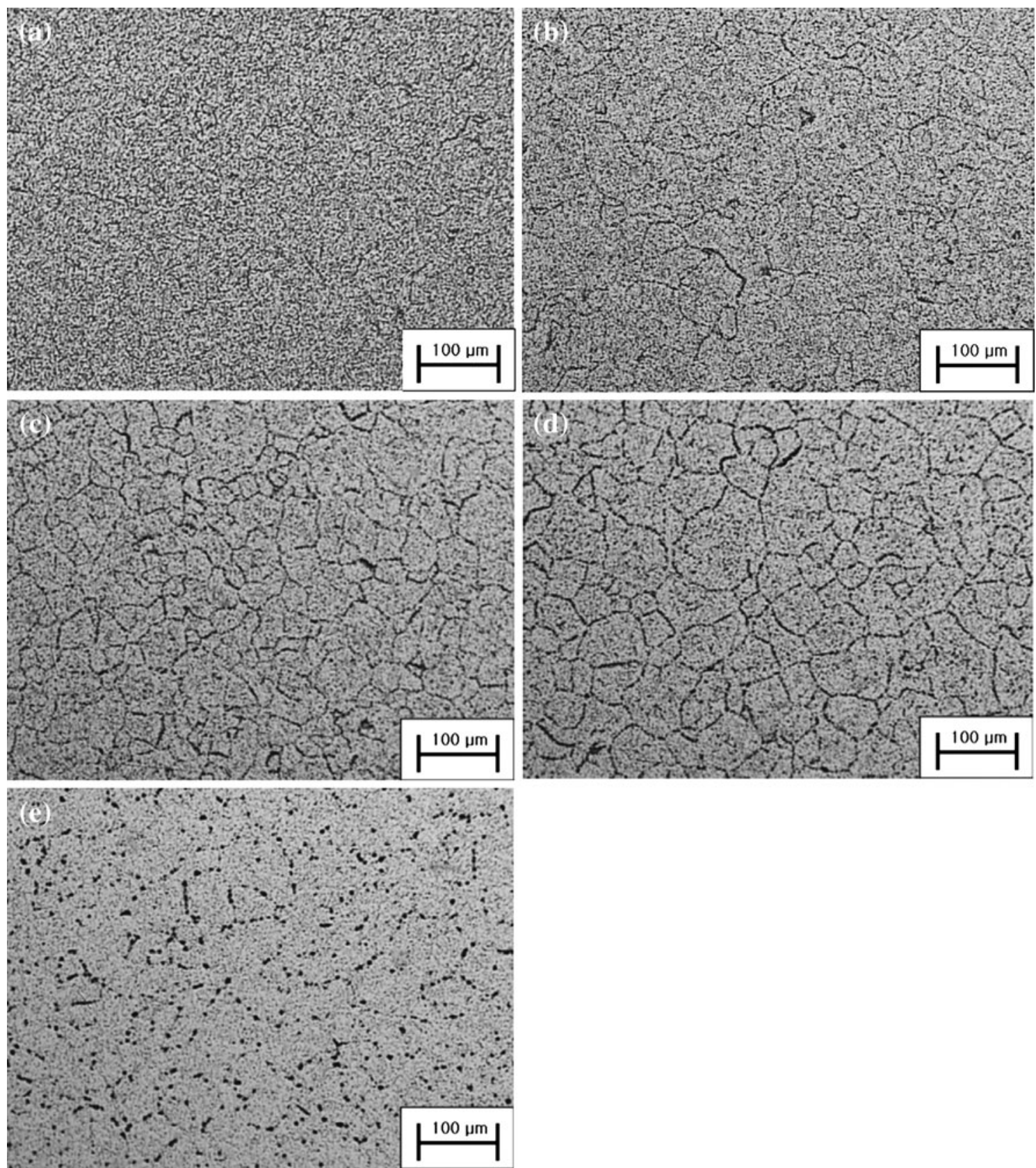

Fig. 2-Boron distribution in the Mo-B steel cooled from $1473 \mathrm{~K}\left(1200{ }^{\circ} \mathrm{C}\right)$ to RT at different rates from $1473 \mathrm{~K}\left(1200{ }^{\circ} \mathrm{C}\right)$ : $(a) 100 \mathrm{~K} / \mathrm{second}$, (b) $40 \mathrm{~K} /$ second, (c) $20 \mathrm{~K} /$ second, (d) $10 \mathrm{~K} /$ second, and (e) $1 \mathrm{~K} /$ second. 
distribution changed at $\mathrm{CR}=1 \mathrm{~K} /$ second; grain boundary precipitates were detected at this slow $\mathrm{CR}$ (Figure 2(e)). These results indicate that the maximum B segregation in the specimen occurs at approximately $10 \leq \mathrm{CR} \leq 20 \mathrm{~K} /$ second in this study.

\section{B. Time Dependence of Boron Distribution in Low Carbon Steel}

Figure 3 shows the distribution behavior of $\mathrm{B}$ with increasing $\mathrm{HT}$ at $T_{H}=1173 \mathrm{~K}\left(900{ }^{\circ} \mathrm{C}\right)$ after cooling from $1473 \mathrm{~K}\left(1200{ }^{\circ} \mathrm{C}\right)$ at $\mathrm{CR}=50 \mathrm{~K} /$ second in the Mo-B steel. After cooling from $1473 \mathrm{~K}$ to $1173 \mathrm{~K}$ $\left(1200{ }^{\circ} \mathrm{C}\right.$ to $\left.900{ }^{\circ} \mathrm{C}\right)$, the $\mathrm{B}$ distribution was nearly homogeneous, and thus, this $\mathrm{CR}$ can be considered to be equivalent to quenching. The degree of segregation increased as HT increased to 60 seconds and then decreased at HT $>60$ seconds. The maximum grain boundary segregation was obtained at $30 \leq \mathrm{HT} \leq$ 60 seconds at $T_{H}=1173 \mathrm{~K}\left(900{ }^{\circ} \mathrm{C}\right)$. The B distribution changed after 1000 seconds at $1173 \mathrm{~K}\left(900{ }^{\circ} \mathrm{C}\right)$; grain boundary precipitates were detected at this isothermal $T_{H}$ (Figure 3(f)). These results indicate that the critical time to reach the maximum grain boundary segregation of $\mathrm{B}$ in the specimen is approximately $30 \leq \mathrm{HT} \leq 60$ seconds.
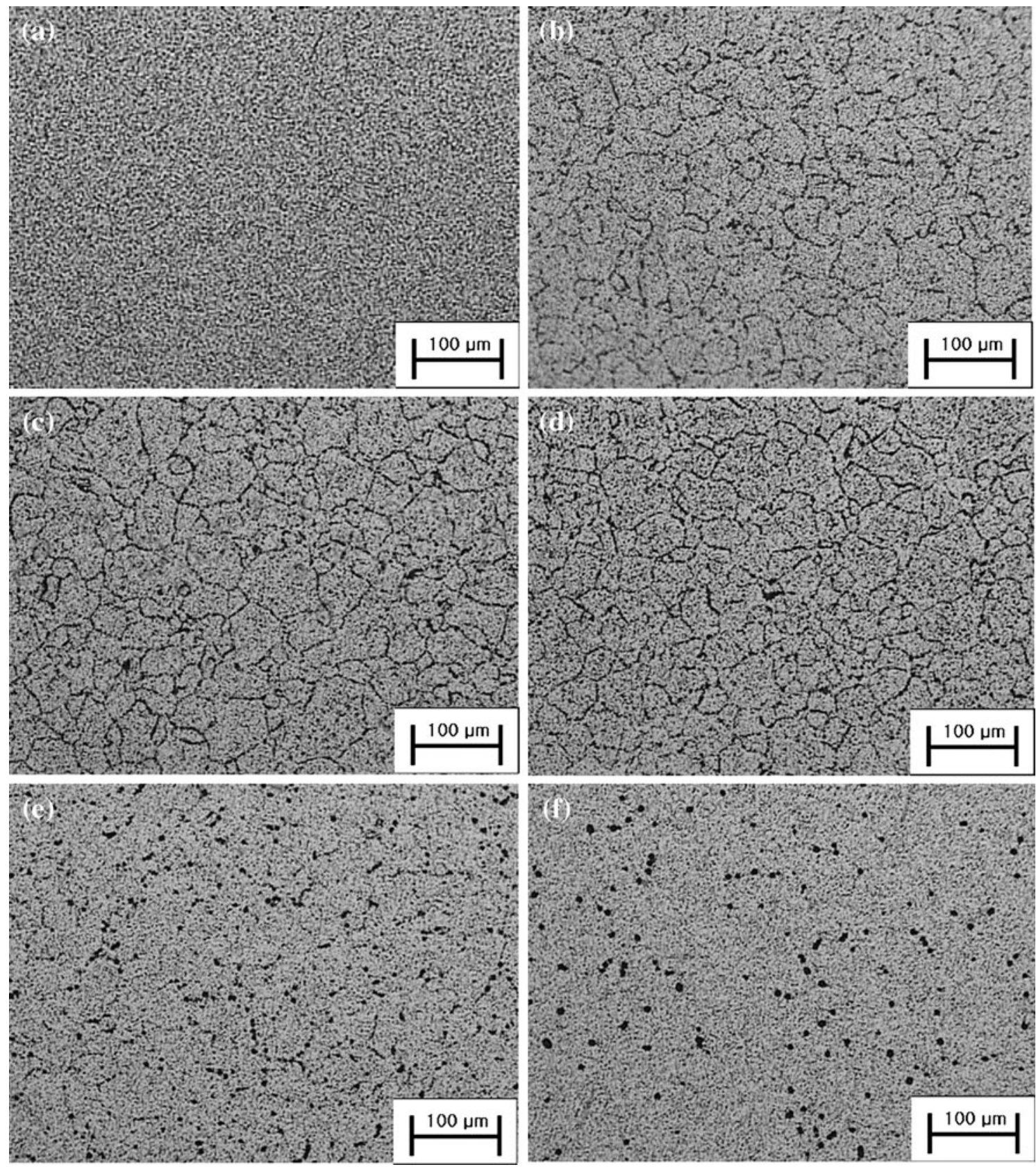

Fig. 3- Boron distribution in the Mo-B steel during isothermal holding at $1173 \mathrm{~K}\left(900{ }^{\circ} \mathrm{C}\right)$ after cooling from $1473 \mathrm{~K}\left(1200{ }^{\circ} \mathrm{C}\right)$ at a $50 \mathrm{~K} / \mathrm{second}$ : (a) 0 seconds, (b) 20 seconds, (c) 30 seconds, (d) 60 seconds, (e) 120 seconds, and (f) 1000 seconds. 


\section{Continuous Cooling Transformation}

Comparison of the continuous cooling transformation between the B-free and B-bearing steels after cooling from $1173 \mathrm{~K}\left(900{ }^{\circ} \mathrm{C}\right)$ is presented in Figure 4. Dotted parallel lines in this figure indicate Bs and Ms temperatures calculated by empirical equations. ${ }^{[22,23]}$ The continuous cooling transformation behavior of B-free steel indicates that the austenite-to-ferrite transformation occurs at $1 \leq \mathrm{CR} \leq 20 \mathrm{~K} /$ second, and thus, the temperature at which transformation starts is depressed to a roughly constant value within this $\mathrm{CR}$ range. The transformation behavior of $\mathrm{B}$-bearing steel was almost the same as that of B-free steel at $\mathrm{CR}=$ $1 \mathrm{~K} /$ second, but the phase transformation of B-bearing steel was retarded to a lower temperature than B-free steel at $\mathrm{CR} \geq 5 \mathrm{~K} /$ second; this retardation effect of $\mathrm{B}$ on phase transformation increased with increasing $\mathrm{CR}$ from 5 to $20 \mathrm{~K} /$ second. The maximum retardation effect of $\mathrm{B}$ occurred at $10 \leq \mathrm{CR} \leq 20 \mathrm{~K} /$ second.

\section{Analysis of Boron Distribution by SIMS}

In the secondary ${ }^{11} \mathrm{~B}^{+}$ion micrographs of the B-bearing steel obtained by SIMS (Figure 5), the B distribution changed according to $\mathrm{CR}$. After cooling from $1173 \mathrm{~K}\left(900^{\circ} \mathrm{C}\right)$, little segregation of $\mathrm{B}$ at grain boundaries was observed at $\mathrm{CR}=1 \mathrm{~K} /$ second, but it was clearly observed at $\mathrm{CR}=5 \mathrm{~K} /$ second and the amount of grain boundary segregation of $\mathrm{B}$ increased with increasing $\mathrm{CR}$ from 5 to $20 \mathrm{~K} /$ second. The maximum grain boundary segregation of $\mathrm{B}$ occurred at $10 \leq \mathrm{CR} \leq 20 \mathrm{~K} /$ second.

\section{E. Microstructure}

In light micrographs of B-free and B-bearing steel cooled at $1 \leq \mathrm{CR} \leq 20 \mathrm{~K} /$ second from $1173 \mathrm{~K}\left(900{ }^{\circ} \mathrm{C}\right)$ (Figures 6 and 7), the microstructures of both specimens were mainly polygonal ferrite at $\mathrm{CR}=1 \mathrm{~K} /$ second. At $\mathrm{CR}=5 \mathrm{~K} /$ second, the final microstructure of $\mathrm{B}$-free

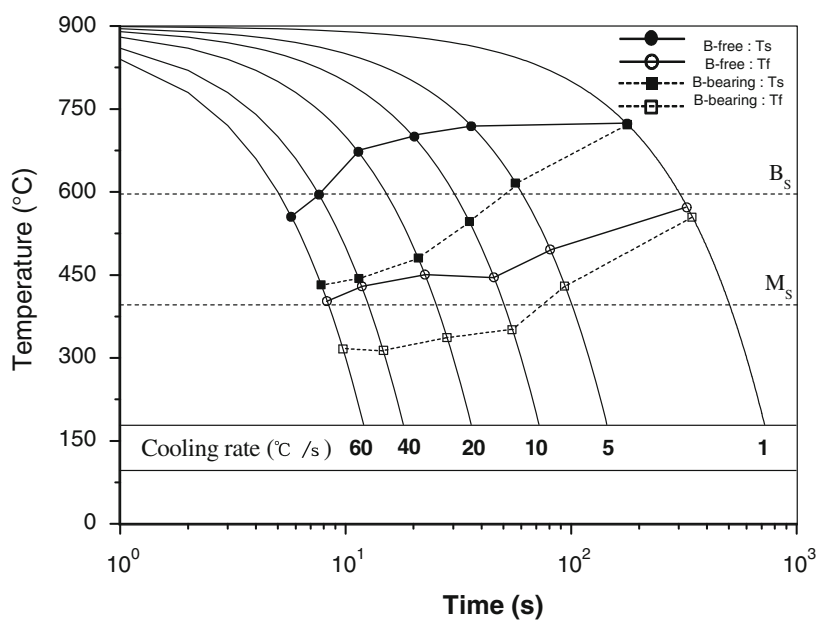

Fig. 4-Comparison of the continuous cooling transformation between B-free and B-bearing steels after cooling from $1173 \mathrm{~K}$ $\left(900{ }^{\circ} \mathrm{C}\right)$. (Ts: Transformation start temperature, Tf: Transformation finish temperature). steel was dominated by polygonal ferrite, but the granular bainitic structure was developed in B-bearing steel. In the B-free steel, the ferrite microstructure became finer and the volume of acicular ferrite increased with increasing CR from 5 to $20 \mathrm{~K} /$ second. In contrast, in the B-bearing steel, the volume of bainitic ferrite increased with increasing $\mathrm{CR}$ from 5 to $20 \mathrm{~K} /$ second.

\section{DISCUSSION}

\section{A. Comparison of Grain Boundary Segregation of Boron Using Effective Time Method}

Based on an isothermal kinetic model for NGS, the concept of effective time that predicts the level of NGS during cooling has been suggested. ${ }^{[14]}$ The effective time method holds that a certain effective HT at a certain $T_{H}$ can be calculated for any continuous cooling curve. If the effective holding time $t_{e}$ during cooling calculated by the effective time method is equal to the critical HT at $T_{H}$, the cooling rate at that time is called the critical cooling rate. ${ }^{[12]}$ This is a basic concept of the effective time method for nonequilibrium segregation.

According to this method, the continuous cooling curve of a specimen can be assumed to be practically equal to the corresponding stepped curve if horizontal and vertical segments of the steps are sufficiently small. If the continuous cooling curve of a specimen is a stepped curve consisting of $n$ steps (Figure 8), $t_{e}$ corresponding to a certain temperature $T$ for each step in the curve can be calculated and $t_{e}$ for the whole curve corresponding to temperature $T$ can be given by ${ }^{[14]}$

$$
\boldsymbol{t}_{\boldsymbol{e}}(\boldsymbol{T})=\sum_{i=1}^{n} \boldsymbol{t}_{i} \exp \left[-\frac{\boldsymbol{E}_{\boldsymbol{A}}\left(\boldsymbol{T}-\boldsymbol{T}_{i}\right)}{k \boldsymbol{T} \boldsymbol{T}_{\boldsymbol{i}}}\right]
$$

where $k$ is Boltzmann's constant and $E_{A}$ is the average activation energy of vacancy and solute atom diffusion in the matrix. $t_{i}$ and $T_{i}$ are the isothermal holding time and temperature at the $i$ th step of the stepped curve, respectively. The main concept of the effective time method is that the average diffusion distance of the diffusant during the cooling of the specimen along the continuous cooling curve is the same as that of a specimen during $t_{e}$ at $T_{H}=T$. Therefore, the amount of $\mathrm{B}$ segregated at the grain boundary during continuous cooling can be predicted easily from the segregation behavior of $\mathrm{B}$ during isothermal holding using the effective time method.

The value of $t_{e}$ during cooling was calculated using Eq. [1], and $E_{A}=1.46 \times 10^{-19} \mathrm{~J}^{[8]}$ was used to calculate the $t_{e}$. In the specimen studied, $t_{e}$ during cooling from $1473 \mathrm{~K}$ to $1173 \mathrm{~K}\left(1200{ }^{\circ} \mathrm{C}\right.$ to $\left.900{ }^{\circ} \mathrm{C}\right)$ at $\mathrm{CR}=1$, 10,20 , and $40 \mathrm{~K} /$ second was $914,91,45$, and 22 seconds, respectively, at isothermal $T_{H}=1173 \mathrm{~K} \quad\left(900{ }^{\circ} \mathrm{C}\right)$. However, this calculation was performed for the ideal case considering perfect quenching. For the real case, $t_{e}$ during cooling from $1473 \mathrm{~K}$ to $1173 \mathrm{~K}\left(1200{ }^{\circ} \mathrm{C}\right.$ to $900{ }^{\circ} \mathrm{C}$ ) at $\mathrm{CR}=50 \mathrm{~K} /$ second is 18 seconds during isothermal holding of $1173 \mathrm{~K}\left(900{ }^{\circ} \mathrm{C}\right)$, and thus, 18 seconds must be subtracted from the calculated values because $\mathrm{CR}=50 \mathrm{~K} /$ second can be considered 

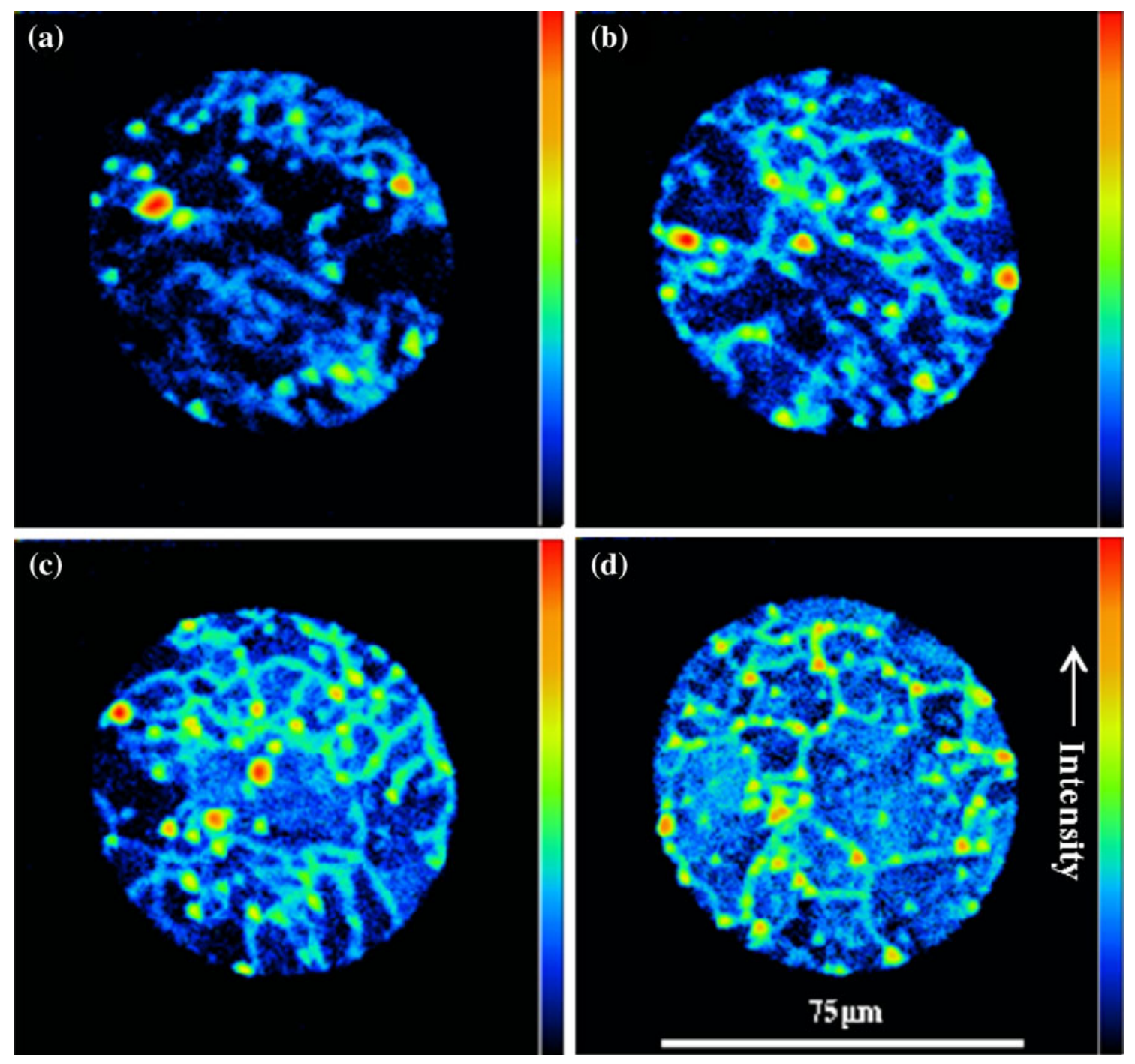

Fig. 5-Secondary ${ }^{11} \mathrm{~B}^{+}$ion images in the B-bearing steel cooled at different cooling rates from $1173 \mathrm{~K}\left(900{ }^{\circ} \mathrm{C}\right)$ : $(a) 1 \mathrm{~K} /$ second, $(b) 5 \mathrm{~K} /$ second, (c) $10 \mathrm{~K} /$ second, (d) $20 \mathrm{~K} /$ second.

equivalent to quenching (Section III-B). The real $t_{e}$ values during cooling from $1473 \mathrm{~K}$ to $1173 \mathrm{~K}\left(1200{ }^{\circ} \mathrm{C}\right.$ to $900{ }^{\circ} \mathrm{C}$ ) at $\mathrm{CR}=1,10,20$, and $40 \mathrm{~K} /$ second were thus 896, 73, 27, and 4 seconds at isothermal $T_{H}=1173 \mathrm{~K}\left(900^{\circ} \mathrm{C}\right)$. Based on this calculation, if the $\mathrm{B}$ distribution during isothermal holding is considered according to the $t_{e}$ corresponding to the cooling rates at isothermal $T_{H}$, the $\mathrm{CR}$ dependence of $\mathrm{B}$ distribution (Figure 2) can be directly compared with its HT dependence at isothermal $T_{H}$ (Figure 3). Although this calculation is based on cooling from $1473 \mathrm{~K}$ to $1173 \mathrm{~K}\left(1200{ }^{\circ} \mathrm{C}\right.$ to $\left.900{ }^{\circ} \mathrm{C}\right)$, it can be applied to continuous cooling from $1473 \mathrm{~K}\left(1200{ }^{\circ} \mathrm{C}\right)$ to $\mathrm{RT}$ because the cooling time below $1173 \mathrm{~K}\left(900{ }^{\circ} \mathrm{C}\right)$ would have little influence on B diffusion. Figure 8 shows the B distribution of Mo-B steel quenched by $\mathrm{He}$ gas at $1073 \mathrm{~K}\left(800^{\circ} \mathrm{C}\right)$ after continuous cooling with 20 and $1 \mathrm{~K} /$ second from $1473 \mathrm{~K}$ to $1073 \mathrm{~K}\left(1200{ }^{\circ} \mathrm{C}\right.$ to $\left.800{ }^{\circ} \mathrm{C}\right)$. This $\mathrm{B}$ distribution is almost the same with the case of continuous cooling from $1473 \mathrm{~K}\left(1200{ }^{\circ} \mathrm{C}\right)$ to RT (Figure 2(c, e)) and the effective time $t_{e}$ during cooling from $1173 \mathrm{~K}$ to $1073 \mathrm{~K}\left(900{ }^{\circ} \mathrm{C}\right.$ to $\left.800{ }^{\circ} \mathrm{C}\right)$ at $\mathrm{CR}=1,10,20$, and $40 \mathrm{~K}$ /second is $69,7,4$, and 2 seconds, respectively, at isothermal $T_{H}=1173 \mathrm{~K}\left(900^{\circ} \mathrm{C}\right)$. This effective time seems to have no significant effect on B diffusion except the slow cooling rate of $1 \mathrm{~K} /$ second. Although the effective time of $1 \mathrm{~K} /$ second, itself 69 seconds, can significantly affect the $\mathrm{B}$ diffusion, the $\mathrm{B}$ distribution will not be changed by this effective time because the state of $\mathrm{B}$ distribution corresponding to $\mathrm{CR}=1 \mathrm{~K} /$ second at isothermal $T_{H}=1173 \mathrm{~K}\left(900{ }^{\circ} \mathrm{C}\right)$ is already stable (Figure 3(f)). Therefore, it is reasonable to compare the $\mathrm{CR}$ dependence of $\mathrm{B}$ distribution during continuous cooling (Figure 2) and the HT dependence at isothermal $T_{H}=1173 \mathrm{~K}\left(900{ }^{\circ} \mathrm{C}\right)$ (Figure 3$)$.

During continuous cooling, the B distribution is nearly homogeneous after cooling from $1473 \mathrm{~K}\left(1200{ }^{\circ} \mathrm{C}\right)$ at $100 \mathrm{~K} /$ second (Figure 2(a)), and thus, this B distribution can be considered the same as 0 seconds (Figure 3(a)) at $1173 \mathrm{~K}\left(900^{\circ} \mathrm{C}\right)$ during isothermal holding. Slight segregation of $\mathrm{B}$ at grain boundaries was observed after cooling at $40 \mathrm{~K} /$ second (Figure 2(b)), and this B distribution falls 

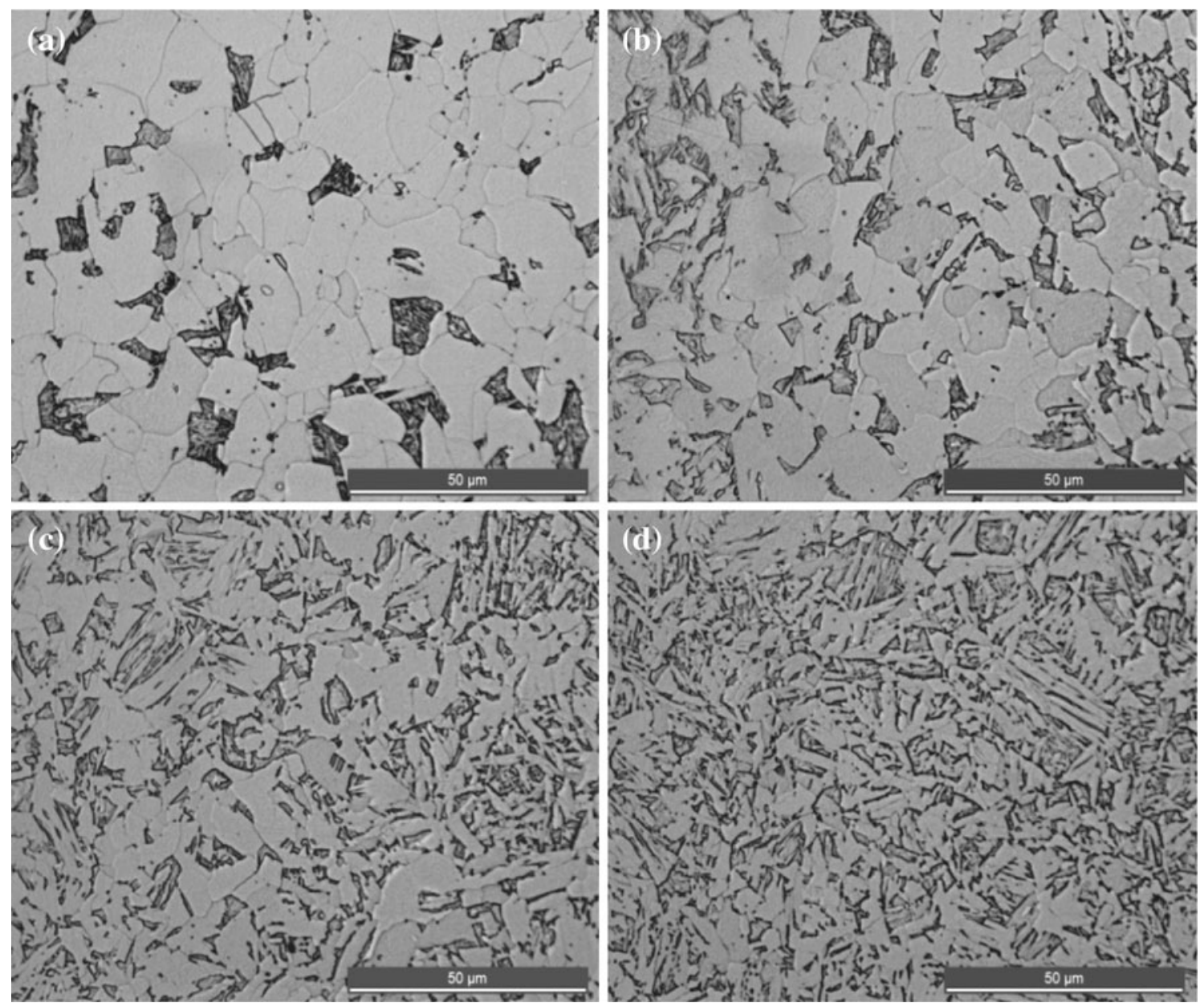

Fig. 6- Optical micrographs of the B-free steel cooled at different cooling rates from $1173 \mathrm{~K}\left(900{ }^{\circ} \mathrm{C}\right)$ : $($ a) $1 \mathrm{~K} /$ second, (b) $5 \mathrm{~K} / \mathrm{second}$, (c) $10 \mathrm{~K} /$ second, (d) $20 \mathrm{~K} /$ second.

on the time between 0 seconds (Figure 3(a)) and 20 seconds (Figure 3(b)) at isothermal $T_{H}=1173 \mathrm{~K}$ $\left(900{ }^{\circ} \mathrm{C}\right)$. Segregation of B along grain boundaries was clearly detected after cooling at $20 \mathrm{~K} /$ second (Figure 2(c)) and $10 \mathrm{~K} /$ second (Figure 2(d)); this B distribution can be connected with 30 seconds (Figure 3(c)) and 60 seconds (Figure $3(\mathrm{~d}))$ at $1173 \mathrm{~K}\left(900{ }^{\circ} \mathrm{C}\right)$. It has been experimentally observed that the maximum grain boundary segregation of B in the specimen occurred at $10 \leq \mathrm{CR} \leq 20 \mathrm{~K} /$ second during continuous cooling and at $30 \leq \mathrm{HT} \leq 60$ seconds during isothermal holding at $1173 \mathrm{~K}\left(900^{\circ} \mathrm{C}\right)$ in this study (Sections III-A and III-B). The effective time is $27 \leq t_{e} \leq 73$ seconds at $1173 \mathrm{~K}$ $\left(900{ }^{\circ} \mathrm{C}\right)$ for the specimen cooled at $10 \leq \mathrm{CR} \leq 20 \mathrm{~K} /$ second, and this effective time agrees reasonably with $30 \leq \mathrm{HT} \leq 60$ seconds, which is experimentally determined as the critical time at isothermal $T_{H}=1173 \mathrm{~K}$ $\left(900{ }^{\circ} \mathrm{C}\right)$. Therefore, $10 \leq \mathrm{CR} \leq 20 \mathrm{~K} /$ second can be considered as the critical cooling rate of the specimen in this study. When the specimen was cooled from $1473 \mathrm{~K}$ to $1173 \mathrm{~K}\left(1200{ }^{\circ} \mathrm{C}\right.$ to $\left.900{ }^{\circ} \mathrm{C}\right)$ at $\mathrm{CR}=1 \mathrm{~K} /$ second (Figure 2(e)), $t_{e}$ at $1173 \mathrm{~K}\left(900{ }^{\circ} \mathrm{C}\right)$ was 896 seconds, and thus, this B distribution can be matched with that in Figure 3(f). Karsson and Norden ${ }^{[9]}$ also showed that the large grain boundary precipitates in B-bearing steel were observed at the lowest CR after austenitization.

In this work, the behavior of $\mathrm{B}$ segregation to grain boundaries during continuous cooling and the isothermal holding process was observed using PTA, and the experimental observations of the CR dependence and HT dependence of B segregation showed that the maximum grain boundary segregation occurs at a certain $\mathrm{CR}$ and at a certain HT. Comparison of the segregation behavior of $\mathrm{B}$ during these two processes using the effective time method indicates that the CR dependence of the grain boundary segregation of $\mathrm{B}$ is in good accordance with its HT dependence at isothermal $T_{H}$, i.e., that the $\mathrm{CR}$ dependence of $\mathrm{B}$ segregation can be explained by its time dependence. This means that the same segregation mechanism operates during both continuous cooling and isothermal holding; thus, the dependence of B segregation on CR and HT can be explained by the nonequilibrium segregation mechanism.

In conclusion, comparison of the $\mathrm{CR}$ dependence and HT dependence of B segregation confirms that the CR dependence of $\mathrm{B}$ segregation in low carbon steel observed in this study is mainly a result of the phenomenon of nonequilibrium segregation. 

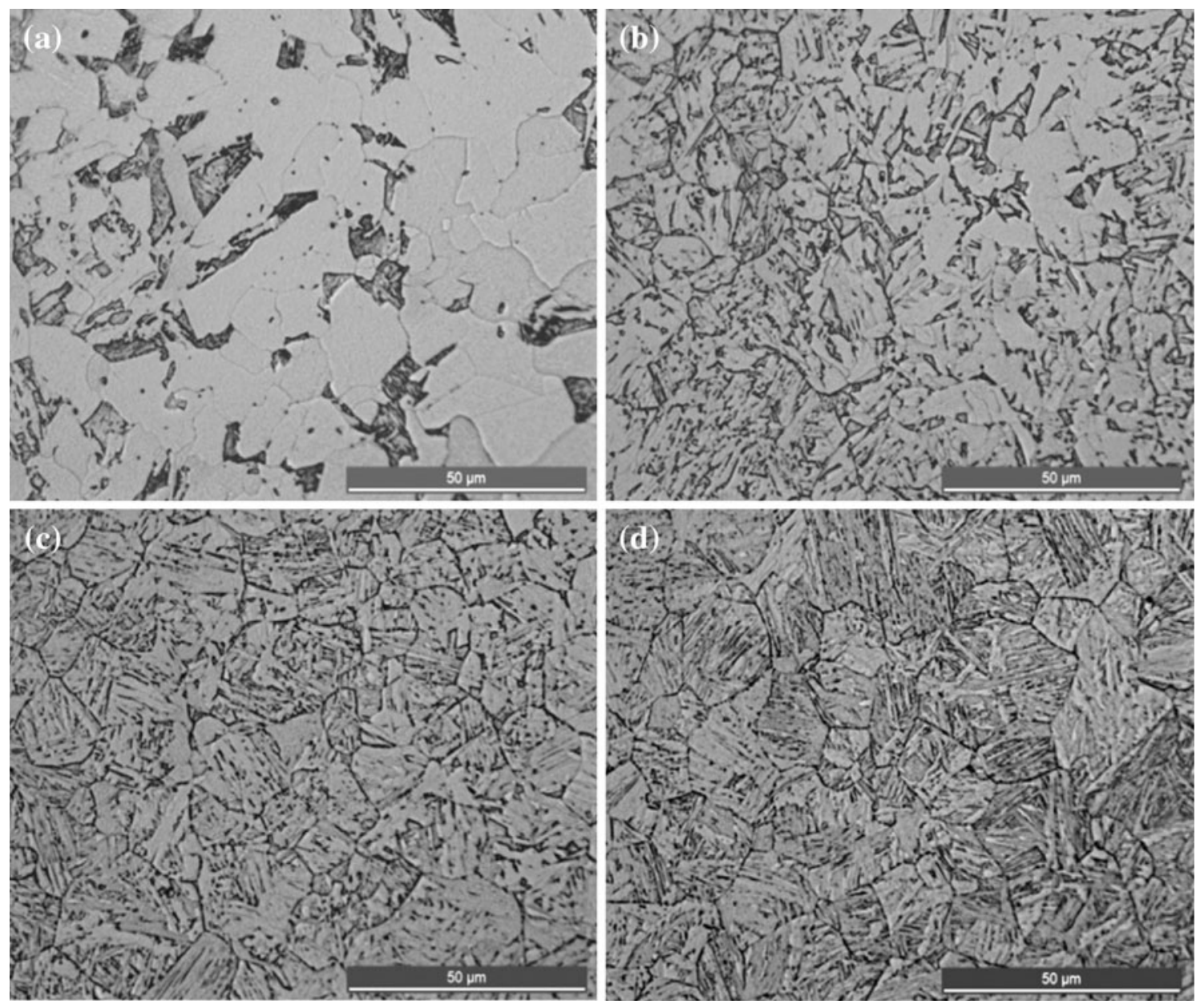

Fig. 7-Optical micrographs of the B-bearing steel cooled at different cooling rates from $1173 \mathrm{~K}\left(900{ }^{\circ} \mathrm{C}\right)$ : $(a) 1 \mathrm{~K} /$ second, $(b) 5 \mathrm{~K} /$ second, $(c)$ $10 \mathrm{~K} /$ second, (d) $20 \mathrm{~K} /$ second.
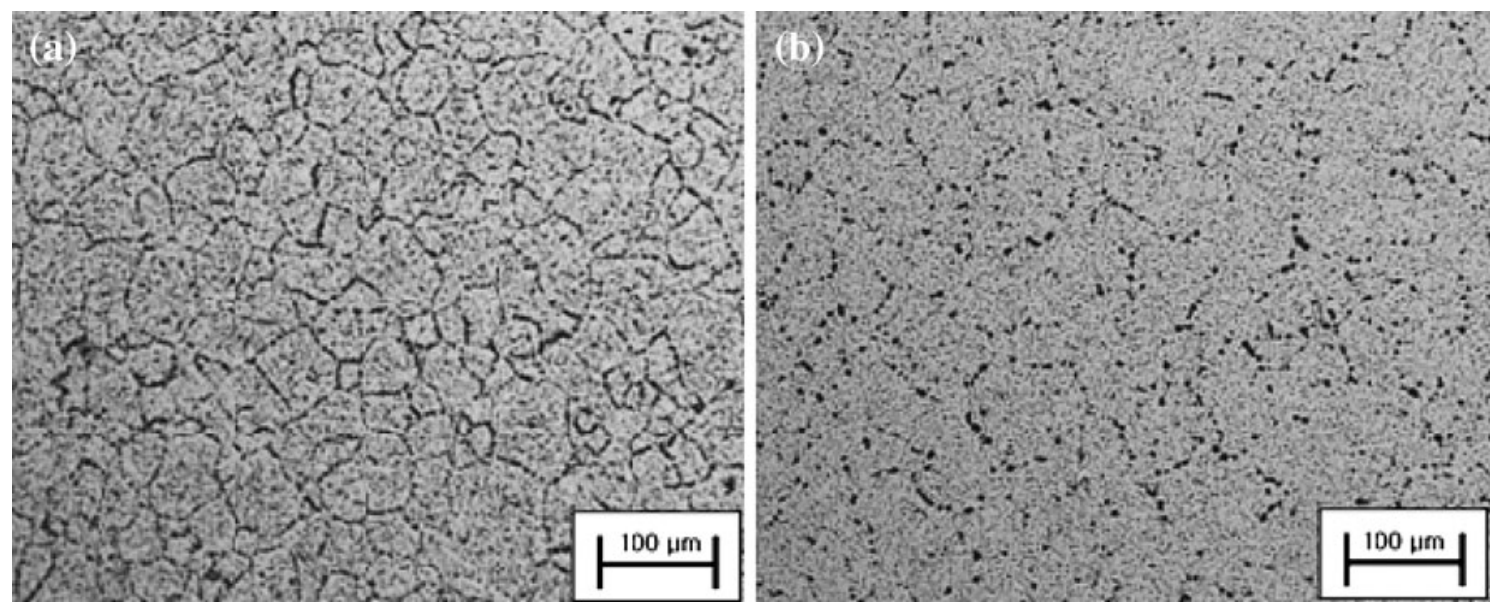

Fig. 8- Boron distribution in the Mo-B steel quenched by He gas after cooling from $1473 \mathrm{~K}$ to $1073 \mathrm{~K}\left(1200{ }^{\circ} \mathrm{C}\right.$ to $\left.800{ }^{\circ} \mathrm{C}\right)$ : $(a) 20 \mathrm{~K} /$ second, (b) $1 \mathrm{~K} /$ second.

\section{B. Phase Transformation Behavior of Boron-Bearing Steel}

It is generally known that the retardation effect of $\mathrm{B}$ on the austenite-to-ferrite transformation occurs by segregation of B atoms at austenite grain boundaries, ${ }^{[24,25]}$ and thus, this retardation effect may be sensitively affected by the segregation behavior of $\mathrm{B}$ during heat treatment.

This study has demonstrated that B segregation to grain boundaries strongly depends on $\mathrm{CR}$ and that this phenomenon is the direct evidence of the nonequilibrium 
segregation. The continuous cooling transformation behavior of B-bearing steel is much different from that of B-free steel (Figure 4). The transformation start temperature of B-bearing steel was almost the same as that of B-free steel at the slowest CR of $1 \mathrm{~K} /$ second, but it was significantly lower than that of B-free steel at $10 \leq \mathrm{CR} \leq 20 \mathrm{~K} /$ second, which is experimentally determined to be the critical CR in this study. The segregation behavior of $\mathrm{B}$ agrees well with the transformation behavior of B-bearing steel as compared with B-free steel (Figure 5). The B distribution clearly shows that the retardation effect of $\mathrm{B}$ on the austenite-to-ferrite transformation occurs by segregation of $\mathrm{B}$ at grain boundaries. The segregation of $\mathrm{B}$ at grain boundaries was not observed at $1 \mathrm{~K} /$ second (Figure 5(a)), but it was clearly observed at $10 \leq \mathrm{CR} \leq 20 \mathrm{~K} /$ second (Figure 5 (c and d)). This distribution behavior of $\mathrm{B}$ is reasonably consistent with the results of CR dependence of $B$ distribution in low carbon steel observed by PTA (Figure 2). Therefore, the effect of $\mathrm{B}$ on phase transformation is directly related to the segregation behavior of $\mathrm{B}$ during cooling. The $\mathrm{CR}$ dependence of $\mathrm{B}$ segregation always occurs in low carbon steel during cooling after austenitization, as a result of the nonequilibrium segregation of B; thus, the effect of $B$ on the retardation of ferrite transformation can be varied depending on $\mathrm{CR}$. The difference of microstructure between B-free (Figure 6) and B-bearing (Figure 7) steel began to occur at a $\mathrm{CR}=5 \mathrm{~K} /$ second, and the most dramatic effect of $\mathrm{B}$ on the microstructure was observed at $10 \leq \mathrm{CR} \leq 20 \mathrm{~K} /$ second. Although the ferrite microstructure was predominant in B-free steel, the bainite microstructure developed in B-bearing steel at $5 \leq \mathrm{CR} \leq 20 \mathrm{~K} /$ second. This means that the addition of a small amount of $B$ to the base steel efficiently suppressed the formation of polygonal ferrite at $5 \leq \mathrm{CR} \leq 20 \mathrm{~K} /$ second and promoted the formation of bainitic microstructures.

From the above experimental results, it can be concluded that the segregation of solute B atoms at austenite grain boundaries causes the transformation temperature of B-bearing steel to differ from that of B-free steel, and this difference finally leads to differences in the microstructure between the two steels. The addition of B to the base steel remarkably decreased the ferrite transformation start temperature and broadened the bainitic transformation field to slower cooling rates. This seems to be attributed to the CR dependence of B segregation during cooling from the austenitizing temperature.

\section{CONCLUSIONS}

A study on the CR dependence of boron distribution in low carbon steel led to the following conclusions.

1. Comparison of the CR dependence and HT dependence of $\mathrm{B}$ segregation using the effective time method in this study indicates that the CR dependence of $\mathrm{B}$ segregation to grain boundaries during continuous cooling is in good agreement with its HT dependence that originates from the isothermal kinetics of $\mathrm{B}$ segregation in low carbon steel and that this segregation behavior of $B$ is mainly a result of the phenomenon of nonequilibrium segregation.

2. The addition of a small amount of B to low carbon steel retarded significantly the austenite-to-ferrite transformation and finally expanded the bainitic transformation field to slower cooling rate regions. This retardation effect of $B$ on ferrite transformation is attributed to the $\mathrm{CR}$ dependence of $\mathrm{B}$ segregation to grain boundaries during cooling after austenitization.

\section{ACKNOWLEDGMENTS}

This research was supported by the WCU (World Class University) program through the National Research Foundation of Korea funded by the Ministry of Education, Science and Technology (R32-10147). The authors would like to thank POSCO for supplying the steels and Dr. B. S. Seong at KAERI for his assistance in irradiation with thermal neutron and autoradiography.

\section{OPEN ACCESS}

This article is distributed under the terms of the Creative Commons Attribution Noncommercial License which permits any noncommercial use, distribution, and reproduction in any medium, provided the original author(s) and source are credited.

\section{REFERENCES}

1. M. Ueno and T. Inoue: Trans. Iron Steel Inst. Jpn., 1973, vol. 13, pp. $210-17$.

2. G.F. Melloy, P.R. Slimon, and P.P. Podgursky: Metall. Trans., 1973, vol. 4, pp. 2279-89.

3. C.R. Simcoe, A.R. Elaea, and G.K. Manning: Trans. AIME, 1956, vol. 206, pp. 984-88.

4. P. Maitrepierre, J. Rofes-Vernis, and D. Thivellier: Boron in Steel, S.K. Banerji and J.E. Morral, eds., AIME, Warrendale, PA, 1979, pp. $1-18$.

5. B.M. Kapadia, R.M. Brown, and W.J. Murphy: Trans. TMSAIME, 1968, vol. 242, pp. 1689-94.

6. R.M. Goldhoff and J.W. Spretnak: Trans. AIME, 1957, vol. 209, pp. $1278-83$

7. T.D. Xu, S. Song, Z. Yuan, and Z. Yu: J. Mater. Sci., 1990, vol. 25 , pp. 1739-44.

8. T.M. Williams, A.M. Stoneham, and D.R. Harries: Met. Sci., 1976, vol. 10, pp. 14-19.

9. L. Karlsson, H. Norden, and H. Odelius: Acta Metall., 1988, vol. 36, pp. 1-12.

10. X. Huang, M.C. Chaurvedi, N.L. Richards, and J. Jackman: Acta Mater., 1997, vol. 45, pp. 3095-170.

11. R.G. Faulker: J. Mater. Sci., 1981, vol. 16, pp. 373-83.

12. S. Song, T.D. Xu, and Z. Yuan: Acta Metall., 1989, vol. 37, pp. 319-23.

13. X.L. He, Y.Y. Chu, and J.J. Jonas: Acta Metall., 1989, vol. 37, pp. 2905-16.

14. T.D. Xu and S. Song: Acta Metall., 1989, vol. 37, pp. 2499-506.

15. H. Asahi: ISIJ Int., 2002, vol. 42, pp. 1150-55.

16. T. Hara, H. Asahi, R. Uemori, and H. Tamehiro: ISIJ Int., 2004, vol. 44 , pp. 1431-40.

17. K.A. Taylor: Metall. Trans. A, 1992, vol. 23A, pp. 107-19.

18. S. Watanabe, H. Otani, and T. Kunitake: Trans. ISIJ, 1983, vol. 23 , pp. 120-27.

19. B.C. Hwang, D.W. Suh, and S.J. Kim: Scripta Mater., 2011, vol. 64 , pp. $1118-20$. 
20. X.L. He and Y.Y. Chu: J. Phys. D, 1983, vol. 16, pp. 1145 58

21. T.B. Cameron and J.E. Morral: Boron in Steel: Proc. Int. Symp. Boron Steels, S.K. Banerjii and J.E. Morral, eds., Metall. Soc. AIME, New York, NY, 1980, pp. 61-79.

22. Y.K. Lee: J. Mater. Sci. Lett., 2002, vol. 21, pp. 1253-55.
23. C. Capdevila, F.G. Caballero, and C.G. de Andrés: ISIJ Int., 2002, vol. 42, pp. 894-902.

24. C.R. Simcoe, A.R. Elaea, and G.K. Manning: Trans. AIME, 1955, vol. 206, pp. 193-200.

25. P. Maitrepierre, D. Thivellier, and R. Tricot: Metall. Trans. A, 1975, vol. 6A, pp. 287-301. 